\title{
MEMS Technology Sensors as a More Advantageous Technique for Measuring Foot Plantar Pressure and Balance in Humans
}

\author{
Clara Sanz Morère, ${ }^{1,2}$ Lukasz Surażyński, ${ }^{1}$ Ana Rodrigo Pérez-Tabernero, ${ }^{1}$ \\ Erkki Vihriälä, ${ }^{1}$ and Teemu Myllylä ${ }^{1}$ \\ ${ }^{1}$ Optoelectronics and Measurement Techniques Unit, University of Oulu, Erkki Koiso-Kanttilankatu 3, 90014 Oulu, Finland \\ ${ }^{2}$ Saints-Pères Faculty of Biomedical Sciences, Paris Descartes University, 45 rue des Saint-Pères, 75006 Paris, France
}

Correspondence should be addressed to Teemu Myllylä; teemu.myllyla@ee.oulu.fi

Received 8 October 2015; Accepted 19 January 2016

Academic Editor: Stephane Evoy

Copyright (C) 2016 Clara Sanz Morère et al. This is an open access article distributed under the Creative Commons Attribution License, which permits unrestricted use, distribution, and reproduction in any medium, provided the original work is properly cited.

\begin{abstract}
Locomotor activities are part and parcel of daily human life. During walking or running, feet are subjected to high plantar pressure, leading sometimes to limb problems, pain, or foot ulceration. A current objective in foot plantar pressure measurements is developing sensors that are small in size, lightweight, and energy efficient, while enabling high mobility, particularly for wearable applications. Moreover, improvements in spatial resolution, accuracy, and sensitivity are of interest. Sensors with improved sensing techniques can be applied to a variety of research problems: diagnosing limb problems, footwear design, or injury prevention. This paper reviews commercially available sensors used in foot plantar pressure measurements and proposes the utilization of pressure sensors based on the MEMS (microelectromechanical systems) technique. Pressure sensors based on this technique have the capacity to measure pressure with high accuracy and linearity up to high pressure levels. Moreover, being small in size, they are highly suitable for this type of measurement. We present two MEMS sensor models and study their suitability for the intended purpose by performing several experiments. Preliminary results indicate that the sensors are indeed suitable for measuring foot plantar pressure. Importantly, by measuring pressure continuously, they can also be utilized for body balance measurements.
\end{abstract}

\section{Introduction}

It goes without saying that feet are the most challenged part of the human anatomy during everyday locomotor activities such as running, jogging, and walking. The effect of these daily exercises on the sole has attracted considerable attention from many researchers for various biomedical applications. Analysis of foot plantar pressure distribution is used, for example, to determine the risk of diabetic foot ulceration, which causes annually over $\$ 1$ billion worth of medical expenses in the United States alone [1]. It is also used in footwear design, to improve balance and to prevent sports injuries.

As this type of analysis has been around for decades, the market is flooded with commercial products offering miniature, lightweight, and energy efficient circuit solutions, while allowing high mobility, spatial resolution, accuracy, and sensitivity.

Nowadays, plantar pressure investigation and production employ two principal configurations: pressure distribution platforms and in-shoe systems. Even if platform devices typically include a greater number of sensors (providing higher resolution), the patient has to be familiarized with the platform (the foot has to hit the center of the sensing area at every step). Due to these and other disadvantages and restrictions, current research focuses largely on in-shoe pressure sensors.

Since the 1990s, several in-shoe measurement configurations have been available on the market [2]. These can be divided into discrete and matrix measurements, depending on sensor arrangement (individual pressure transducers or arrays of sensors organized in rows and columns), but can 


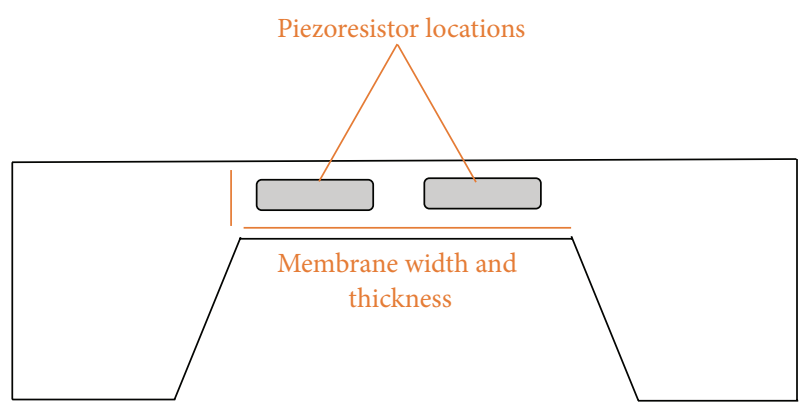

FIGURE 1: Diagram of a MEMS pressure sensor.

also be categorized depending on the physical technique used.

While microcapsules are no longer used, pedoscopes still have their place in the medical community. But the most common types are resistive, capacitive, and piezoresistive sensors, which will be explained below [3].

Technology keeps moving forward and new types of sensors are being developed to enhance accuracy, sensitivity, linearity, hysteresis, pressure range, repeatability, cost, and power consumption. As weaknesses have emerged in already existing sensors, a new and improved technique is being developed to address these shortcomings. Employing a microelectromechanical (MEMS) pressure sensor, the new technique has considerably enhanced performance characteristics [4].

MEMS technology now spans a wide range of applications across a multitude of disciplines. For example, the use of a MEMS oscillator for military purposes has proven highly efficient [5]. In the medical sector, MEMS sensors have been applied since 1980 [6]. To show the power of this technology in medicine, it suffices to introduce two outstanding commercial products: the MEMS Hearing-Aid Transducer (an electroacoustic device used to receive, amplify, and radiate sound into the ear) [7] and the iBOTTM Mobility system (one of the most unique wheelchairs) [8].

As these great achievements are the result of inexpensive and easy integration of MEMS technologies, the potential of MEMS sensors should be explored in the design of a new generation of gait analysis instruments [4].

This study presents different already existing sensors and describes pressure sensors based on the MEMS technique, which, due to improved characteristics, can be applied to measuring foot plantar pressure. The basic structure of a MEMS pressure sensor is illustrated in Figure 1. Several tests were performed to evaluate the sensors' suitability for pressure measurements, including balance testing and gait analysis.

\section{Sensing Techniques Used in Foot Plantar Pressure Sensors}

Current sensors can be divided into resistive, capacitive, and piezoresistive sensors. The principle of resistive pressure measurements is based on measuring changes in the resistance of electronic conductors caused by pressure-dependent deflections, which is measured using metallic strain gauges: when the main body deflects under the action of pressure, the strain gauges deflect correspondingly. Electrical resistance changes in proportion to the deflection [4]. Resistive sensors are used, for instance, by Tekscan in the so-called ForceSensing Resistor (FSR) method, with two Mylar sheets with a conductive polymer layer embedded between them. With this sensor, it is possible to capture temporal parameters, pressure, and force, making them suitable for different applications, such as designing and testing orthotics [9]. However, a high hysteresis seems to be a notable weakness of this technique.

A capacitive sensor consists of two charged plates made of a conducting material, separated by a dielectric elastic layer. When pressure is applied, the distance between the plates decreases. As a result, capacitance increases, changing the measured voltage. A quantitative assessment of pressure is achieved by utilizing a calibration curve developed for each sensor in the matrix [3]. While this technique presents very little or no hysteresis, the main practical restrictions arise from its thickness and type of material. Commercial products based on this system include EMED platform systems (Novel, Germany) and Pedar in-shoe systems (Novel, Germany) [10].

The principle of piezoresistive sensors is similar to the principle of resistive pressure measurements. However, since the strain gauges used for this measuring principle are made of a semiconductor material, it is their deflection that results in a change in resistivity [11]. Piezoresistive sensors have lower production costs when compared to capacitive pressure sensors, which makes them more profitable for some applications, and can also be used in very low pressure ranges. However, individual temperature compensation of every single sensor is required [5].

In general, the required key specifications for a pressure sensor in terms of sensor performance include linearity, low hysteresis, operating frequency of at least $200 \mathrm{~Hz}$, no creep and repeatability, temperature sensitivity $\left(20^{\circ} \mathrm{C}\right.$ to $\left.37^{\circ} \mathrm{C}\right)$, specific sensing size, sufficient pressure range, and proper sensor placement [10]. MEMS techniques are a step forward from all already existing sensors. MEMS devices are made up of miniaturized mechanical and electromechanical elements using microfabrication techniques. MEMS sensors have been analysed since the 1950s, but their use in medical applications is much more recent. Many principles can be used for MEMS technology, the most important one (the one further studied) being the piezoresistive sensor. As already explained, piezoresistive transducers contain piezoresistors, which are materials that produce a change in resistance proportional to the applied stress.

The relationship between piezoresistance change and stress is represented by the following linear equation [10]:

$$
R=R_{O}\left(1+\pi_{L} \sigma_{L}+\pi_{T} \sigma_{T}\right)
$$

where $R$ is piezoresistor's resistance value when external pressure is applied, $R_{O}$ is piezoresistor's resistance without any applied pressure, $\Pi_{L}$ is piezoresistance coefficient for longitudinal direction, $\Pi_{T}$ is piezoresistance coefficient for 
TABLE 1: Technical specifications of some existing sensors and 2 different MEMS proposals [12].

\begin{tabular}{|c|c|c|c|c|c|c|}
\hline & Teksan & Novel & Parotec & MEMS [4] & $\begin{array}{l}\text { Sensors } 1 \text { and } 3 \\
\text { MPX2202A [13] }\end{array}$ & $\begin{array}{l}\text { Sensors } 2 \text { and } 4 \\
\text { MPX5999D [14] }\end{array}$ \\
\hline Sensor size & $0.15 \mathrm{~mm}$ thick & $1.9 \mathrm{~mm}$ thick & $4 \mathrm{~cm}^{2}$ & $2 \mathrm{~mm}$ thick & $\begin{array}{c}5.08-5.59 \mathrm{~mm} \\
\text { thick }\end{array}$ & $\begin{array}{c}5.08-5.59 \mathrm{~mm} \\
\text { thick }\end{array}$ \\
\hline Number of sensors & 960 & 99 & 24 & 15 & 1 & 1 \\
\hline Range (kPa) & 1034 & 1200 & 625 & 3000 & 200 & 1000 \\
\hline Frequency $(\mathrm{Hz})$ & 500 & Not specified & 250 & 200 & Not specified & Not specified \\
\hline Hysteresis & $24 \%$ & $<7 \%$ & $\begin{array}{c}0.05 \% \text { at } \\
20 \mathrm{Ncm}^{-1}\end{array}$ & Negligible & $0.1 \%$ & $\begin{array}{c}\text { Accuracy of } 2.5 \% \\
\text { taking into account } \\
\text { linearity, } \\
\text { temperature and } \\
\text { pressure hysteresis, } \\
\text { offset and span }\end{array}$ \\
\hline
\end{tabular}

transversal direction, $\sigma_{T}$ is average transversal stress across the piezoresistor, and $\sigma_{L}$ is average longitudinal stress along the piezoresistor.

After pressing the sensor between the foot sole and the ground, the piezoresistor changes its relative dimensions and, as the resistance is related to its length and crosssectional area, the ensuing resistance changes (following (1)) are proportional to the applied stress and, thus, to pressure.

The use of pressure sensors made of conductive polymers is common in biomechanical applications [15]. Unfortunately, hysteresis, nonlinearity, nonrepeatability, and creep have a significant effect on pressure readings when such conductive polymers are used. Therefore, we propose to use the MEMS pressure sensor system with a new alternative setup.

Material, size, and shape of the sensors are critical, because they are directly related to the performance of the sensor. For example, different materials can produce different resistance changes to the same pressure and so happens with piezoresistors of different geometries [4]. The piezoresistor should thus be selected in order to satisfy the needs of each application in both material performance and geometry characteristics. Otherwise, if they are not appropriate to the specific application, errors or saturation would occur and the measurements would be mistaken. The most common material is silicone with a thin membrane having thicknesses of $100 \mu \mathrm{m}, 200 \mu \mathrm{m}$, and $278 \mu \mathrm{m}$ [10]. Moreover, a square shape membrane is capable of providing high stress areas, as high as 1.64 times as compared to a circular one $[4,16]$. Moreover, a square shaped membrane is capable of providing high stress areas, up to 1.64 times relative to a circular one $[4,16]$.

Another characteristic that a MEMS sensor system improves when compared with other sensors is hysteresis, which can be determined by observing the output signal while the sensor is being loaded and unloaded. According to literature, hysteresis in a MEMS system is negligible, making it one of the few commercial sensor types where hysteresis is insignificant [17].

As shown in Table 1 [12], the maximum sampling frequency of a MEMS sensor is $200 \mathrm{~Hz}$ which is not as high as that of many other sensors, such as piezoelectric sensors [18]. However, it has been demonstrated and explained in biomechanical evaluations of movement in sports and exercise [19] that an analysis of foot loading profiles requires a sampling rate of at least $100 \mathrm{~Hz}$. For high-speed activities, the required sampling frequency is approximately $200 \mathrm{~Hz}$. Hence, the maximum sampling frequency of MEMS pressure seems sufficient.

Moreover, it is essential to focus on the key specification for a pressure sensor: pressure range puts MEMS technology at the forefront of pressure measurement systems. The pressure range of Novel, Parotec, and Textile sensors are lower than that of a MEMS measurement sensor [12]. Generally speaking, it has been demonstrated [20] that pressure ranges (normally because of increasing error and decreasing linearity) are lower for commercial products than for MEMS.

As this trait is fundamental to measuring pressure, the required range usually varies depending on the application. For foot plantar pressure, values close to $1900 \mathrm{kPa}$ have been reported in the literature [21]. Thus, MEMS pressure sensors, due to their high pressure range, are the most appropriate sensor for measuring ordinary gait.

MEMS technology is very promising and has been extensively studied and already utilized in many application areas, for instance, in automotive, aerospace, and telecommunication systems. MEMS seems to have outstanding characteristics in comparison to resistive and capacitive sensors, with lower hysteresis, higher pressure range, and insensitivity to temperature.

\section{Materials and Measurement Method}

Two MEMS pressure sensors manufactured by Freescale Semiconductor were used in the measurements MPX2202A and MPX5999D [13, 14], with different sensitivities and slightly different dimensions. With a sensitivity of $4.5 \mathrm{~V} / \mathrm{kPa}$, MPX5999D was placed on the toe-side, while MPX2202A, with a lower sensitivity of $0.2 \mathrm{~V} / \mathrm{kPa}$, was placed on the heelside. In these measurements, we used the sensor placement shown in Figure 2.

Figure 3 illustrates the method of embedding sensors in a shoe. A common type of shoe was used in our experiments, with the shoe body consisting of two main layers, insole and outsole, both made of thermoplastic rubber. The sensors 


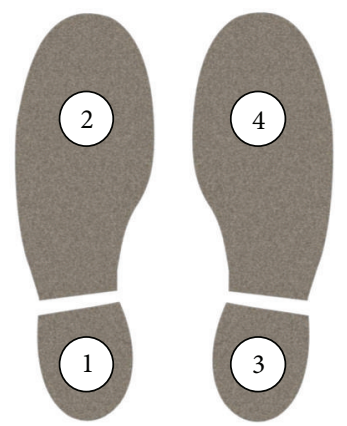

Figure 2: Sensor placement in the shoes. Sensors 1 and 3 (hill-side) are model MPX2202A and sensors 2 and 4 (toe-side) are model MPX5999D.

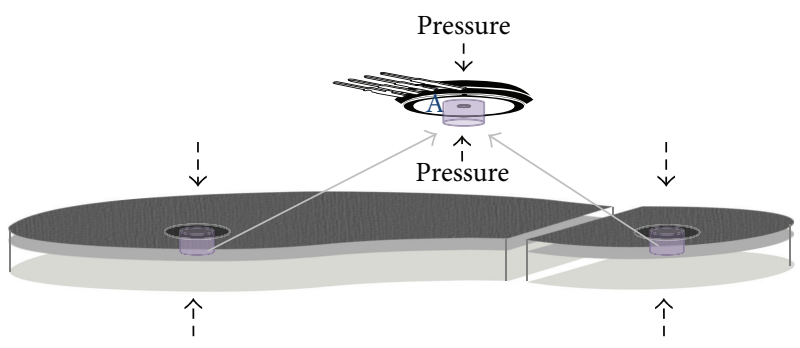

FIGURE 3: Embedding of pressure sensors in a shoe. The thickness of the sensors (A) is 5-6 mm and their diameter is approximately $15 \mathrm{~mm}$. They are embedded airtight to enable sensing of pressure inside the pressure chamber, shown below the sensor.

were embedded in the outsole, which had a thickness of approximately $30 \mathrm{~mm}$ on the heel-side and $15 \mathrm{~mm}$ on the toe-side. The insole layer had an overall thickness of $5 \mathrm{~mm}$ and was removed to enable placing the sensors within the outsole layer, before being glued back on top of the outsole layer. Electrical wires for the sensors were placed between these layers. For each sensor, a housing cavity was drilled into the upper side of the outsole layer. Then, below the housing cavity, a pressure chamber was drilled for the sensor. This chamber was cylindrical in shape, with a diameter of approximately $7 \mathrm{~mm}$ and a depth of $5 \mathrm{~mm}$, illustrated in Figure 3 as a turquoise coloured cylinder below the sensor. Finally, silicon glue was used to attach the sensor airtight into the housing to enable pressure sensing inside the chamber. In principle, pressure inside the elastic chamber changes when a force, such as foot plantar pressure, acts in its proximity. Sensitivity and sensing area were optimized by experimenting with the size of the pressure chamber. Using the chamber size mentioned above, the sensitive (round) area on the bottom side of the shoe was approximately $7 \mathrm{~cm}^{2}$.

MPX2202A is a silicone piezoresistive pressure sensor, built on a monolith silicon diaphragm with a strain gauge and resistor network on a chip, which is temperature and offset compensated. The range of the sensor is fixed between 0 and $200 \mathrm{kPa}(29 \mathrm{psi})$ with a $40 \mathrm{mV}$ full-scale output. The other model, MPX5999D, is an integrated piezoresistive transducer, which is also able to maintain a linear voltage output proportional to applied pressure. This device has a wider pressure range, $0-1000 \mathrm{kPa}(150 \mathrm{psi})$, with $4.5 \mathrm{~V}$ of full-scale output with a minimum offset of $200 \mathrm{mV}$. The sensor's supply voltage was $+10 \mathrm{~V}_{\mathrm{DC}}$. Shown in Figure 4 is the circuit design, built on OPA4227 operational amplifiers. Each channel was buffered with noninverting differential inputs. Next, an amplifying stage with adjustable gain and simple low-pass filtering was added. A cut-off frequency of $30 \mathrm{~Hz}$ was chosen, because, in terms of our experiments, slow changes in body balance were of most interest. Additional filtering was implemented by a Sallen-Key low-pass filter with the same cut-off frequency. The circuit was powered with a differential supply of $\pm 10 \mathrm{~V}_{\mathrm{DC}}$, which required approximately $80 \mathrm{~mA}$ of current. Output signals were acquired using a National Instruments USB-6008 data acquisition card, connected to a laptop.

Naturally, in addition to the embedding method and features of the sensor itself, the sensitivity and dynamics of the sensor also depend on the amplification of its output signal. Optimal amplification was obtained by adjusting the amplifier's trimmer with the subject first standing and then moving about with the shoes on. First, however, the output voltage of each sensor was set near its maximum with the subject standing on one leg. This voltage level corresponds to the weight of the subject, while the minimum voltage reading, recorded with no weight on the shoe, when the subject lifted a leg, corresponds to the weight of $0 \mathrm{~g}$. It should be noted that although the sensors provide linear voltage output directly proportional to the applied pressure, the recorded voltage 


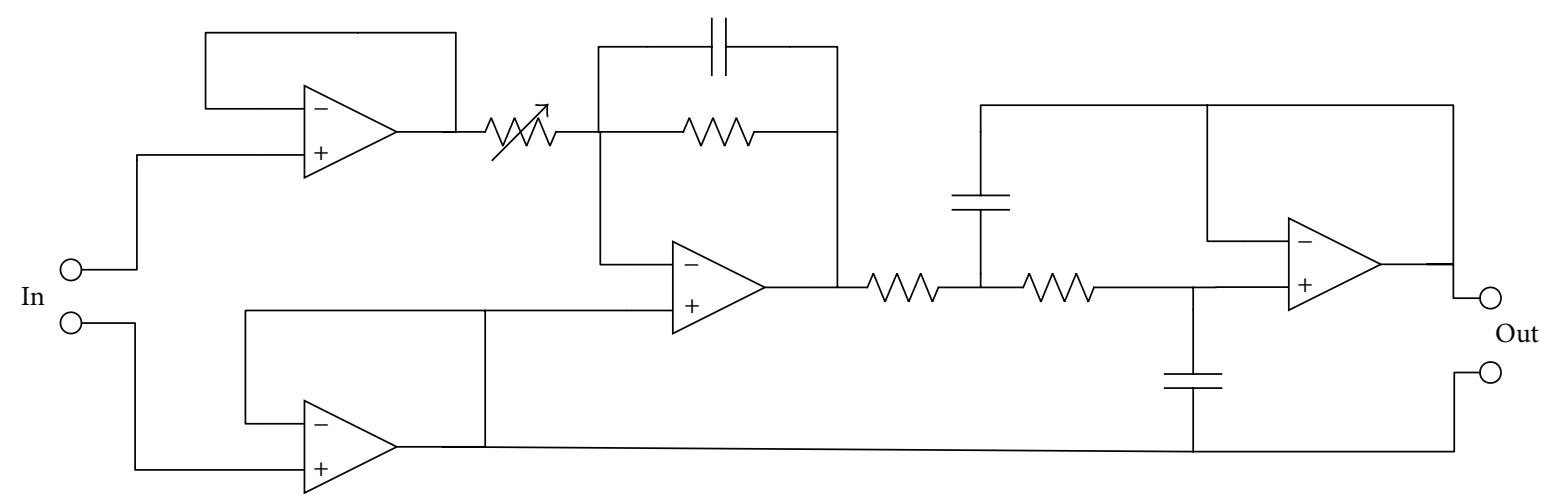

FIGURE 4: An adjustable differential amplifier circuit with Sallen-Key low-pass filtering for the pressure sensor.

TABLE 2: The nine different setups performed during the tests.

\begin{tabular}{lll}
\hline Setup 1 & Standing & Standing at rest and then lifting one leg at a time. \\
Setup 2 & Balancing left/right & Balancing from right foot to left foot, first slowly (light) and then quicker. \\
Setup 3 & Balancing front/back & Balancing from front to back in a constant sequence (each $10 \mathrm{~s}$ ). \\
Setup 4 & Swinging counterclockwise & Rotating hips to induce pressure changes. \\
Setup 5 & Lifting legs & Similar to the first one, but moving quicker, thus making the force applied by the foot stronger. \\
Setup 6 & Walking & Untutored walk for $60 \mathrm{~s}$. \\
Setup 7 & Coughing, laughing & 5 s of coughing followed by $5 \mathrm{~s}$ of laughing between resting states. \\
Setup 8 & Adding weight & Three different weights given to the subject in a sequence. \\
Setup 9 & Jumping & Three slow $5 \mathrm{~s}$ ) jumps followed by 5 consecutive small jumps of $1 \mathrm{~s}$ duration. \\
\hline
\end{tabular}

TABLE 3: Voltage values for standing.

\begin{tabular}{lccccc}
\hline \multicolumn{1}{c}{ Standing } & \multicolumn{4}{c}{ Pressure values for setup 1 } \\
& & $\begin{array}{c}\text { Front } \\
\text { left }\end{array}$ & $\begin{array}{c}\text { Front } \\
\text { right }\end{array}$ & $\begin{array}{c}\text { Heel } \\
\text { left }\end{array}$ & $\begin{array}{c}\text { Heel } \\
\text { right }\end{array}$ \\
\hline Rest & $0-10 \mathrm{~s}$ & 0.15 & 0.64 & 0.45 & 0.37 \\
Left up & $10-20 \mathrm{~s}$ & 0.34 & 0.33 & 0.84 & 0.01 \\
Right up & $20-30 \mathrm{~s}$ & 0.15 & 0.84 & 0.13 & 0.87 \\
Left up & $30-40 \mathrm{~s}$ & 0.12 & 0.06 & 0.79 & 0.02 \\
Right up & $40-50 \mathrm{~s}$ & 0.23 & 0.30 & 0.19 & 0.70 \\
Left up & $50-60 \mathrm{~s}$ & 0.22 & 0.19 & 0.63 & 0.51 \\
\hline
\end{tabular}

readings do not provide an accurate absolute weight value for a person, because sensor responses are continuously affected by tiny balance shifts.

\section{Results}

Nine different experiments were performed and analysed in order to demonstrate the usability of MEMS pressure sensors for foot plantar pressure as well as for body balance measurements. A summary of the different set ups can be seen in Table 2. Two test subjects participated in the experiments, a male, with a height of $186 \mathrm{~cm}$ and weight of $73 \mathrm{~kg}$, and a female, with a height of $165 \mathrm{~cm}$ and a weight of $68 \mathrm{~kg}$. After performing the 9 different setups, time-dependent voltage values were obtained for each of the four sensors.
TABLE 4: Voltage values during balancing front/back setup.

\begin{tabular}{lccccc}
\hline \multicolumn{1}{c}{ Balancing front/back } & \multicolumn{4}{c}{ Voltage values for setup 3 } \\
& & $\begin{array}{c}\text { Front } \\
\text { left }\end{array}$ & $\begin{array}{c}\text { Front } \\
\text { right }\end{array}$ & $\begin{array}{c}\text { Heel } \\
\text { left }\end{array}$ & $\begin{array}{c}\text { Heel } \\
\text { right }\end{array}$ \\
\hline Resting & $0-10 \mathrm{~s}$ & 0.19 & 0.13 & 0.15 & 0.69 \\
Front & $10-20 \mathrm{~s}$ & 0.73 & 0.67 & 0.06 & 0.03 \\
Back & $20-30 \mathrm{~s}$ & 0.09 & 0.04 & 0.78 & 0.55 \\
Front & $30-40 \mathrm{~s}$ & 0.99 & 0.96 & 0.09 & 0.04 \\
Back & $40-50 \mathrm{~s}$ & 0.11 & 0.14 & 0.92 & 0.65 \\
Front & $50-60 \mathrm{~s}$ & 0.18 & 0.26 & 0.14 & 0.63 \\
\hline
\end{tabular}

TABLE 5: Voltage values for the adding weight setup.

\begin{tabular}{lccccc}
\hline \multicolumn{1}{c}{ Adding weight } & \multicolumn{4}{c}{ Voltage values for setup 8 } \\
& & $\begin{array}{c}\text { Front } \\
\text { left }\end{array}$ & $\begin{array}{c}\text { Front } \\
\text { right }\end{array}$ & $\begin{array}{c}\text { Heel } \\
\text { left }\end{array}$ & $\begin{array}{c}\text { Heel } \\
\text { right }\end{array}$ \\
\hline Resting & $0-10 \mathrm{~s}$ & 0.17 & 0.04 & 0.65 & 0.41 \\
Weight 1 & $10-20 \mathrm{~s}$ & 0.34 & 0.27 & 0.49 & 0.51 \\
Weight $1+2$ & $20-30 \mathrm{~s}$ & 0.37 & 0.38 & 0.49 & 0.55 \\
Weight $1+2+3$ & $30-40 \mathrm{~s}$ & 0.55 & 0.56 & 0.53 & 0.52 \\
Rest & $40-50 \mathrm{~s}$ & 0.17 & 0.12 & 0.58 & 0.63 \\
\hline
\end{tabular}

Voltage readings after offset compensation can be seen in Tables 3-6. The mean values for the responses were calculated for the time the subject was performing each task. As the 
TABLE 6: Voltage values for the jumping setup.

\begin{tabular}{cccccc}
\hline \multicolumn{1}{c}{ Jumping } & \multicolumn{4}{c}{ Voltage values for setup 9 } \\
& $\begin{array}{c}\text { Front } \\
\text { left }\end{array}$ & $\begin{array}{c}\text { Front } \\
\text { right }\end{array}$ & $\begin{array}{c}\text { Heel } \\
\text { left }\end{array}$ & $\begin{array}{c}\text { Heel } \\
\text { right }\end{array}$ \\
\hline Resting & $0-10 \mathrm{~s}$ & 0.18 & 0.13 & 0.58 & 0.34 \\
Jump 1 & $10-20 \mathrm{~s}$ & 0.20 & 0.05 & 0.48 & 0.39 \\
Jump 2 & $15-20 \mathrm{~s}$ & 0.33 & 0.01 & 0.31 & 0.25 \\
Jump 3 & 20-21 s & 0.46 & 0.35 & 0.09 & 0.25 \\
Jump 4 & $21-22 \mathrm{~s}$ & 0.81 & 0.43 & 0.53 & 0.63 \\
Jump 5 & $22-23 \mathrm{~s}$ & 0.40 & 0.24 & 0.19 & 0.28 \\
Jump 6 & $23-24 \mathrm{~s}$ & 0.66 & 0.51 & 0.05 & 0.18 \\
Jump 7 & $24-25 \mathrm{~s}$ & 0.94 & 1.00 & 0.07 & 0.03 \\
Resting & $25-30 \mathrm{~s}$ & 0.38 & 0.26 & 0.57 & 0.31 \\
\hline
\end{tabular}

MEMS sensors are piezoresistive, the voltage value measured is related to the resistance change. However, it changes as a function of the force applied to the sensors, following (1). The exact relationship between voltage and pressure could be determined by using a more sophisticated calibration method and should be used in posterior studies to fully exploit the utility of MEMS in gait analysis. However, presented normalized voltage values demonstrate that MEMS sensors measure voltage differences that agree with the different patterns of the setup. For example, during standing on left or right foot, the voltage values alternate from left to right in the same period than the alternation of foot. The values of the left sensors increase when the subject stands on left foot and vice versa. This can be easily seen in the different patterns from different trials that can be found in Figures 5-9. The patterns look as expected and corroborate the voltage results.

Focusing on Figure 7, it can be seen that voltages obtained for left and right foot differ. Both have similarities with a typical heel pattern during walk, as there is a principal peak that corresponds to heel strike (when heel hits the ground). There is also a smaller peak that would correspond to the shoe bouncing after toe push (when toes push the ground to lift the leg up). But the signals show a major difference in the amplitude of the voltages, which is related to the pressure ranges of the sensors. Both signals were measured using MPX2202A sensor, which has a range of $200 \mathrm{kPa}$.

As previously mentioned, the characteristics of the sensors should be appropriately chosen depending on the application, and in this case, according to literature, pressure ranges should be at least as high as $1900 \mathrm{kPa}$. A lower pressure range leads to inaccurate voltage measurements, as sensors can saturate. The differences between left and right legs are not very well understood in this case. It could be due to disorders in the tested subject, to a different placement of the sensors (lack of symmetry), or even to the normal gait pattern of the subject, which is unique, and might put higher pressure in the right foot while walking. Gait analysis could be more deeply analysed by comparing also the toe pattern in both legs. In addition, these differences between left and right foot should be further studied first by choosing the sensor model with a higher pressure range and then by testing higher
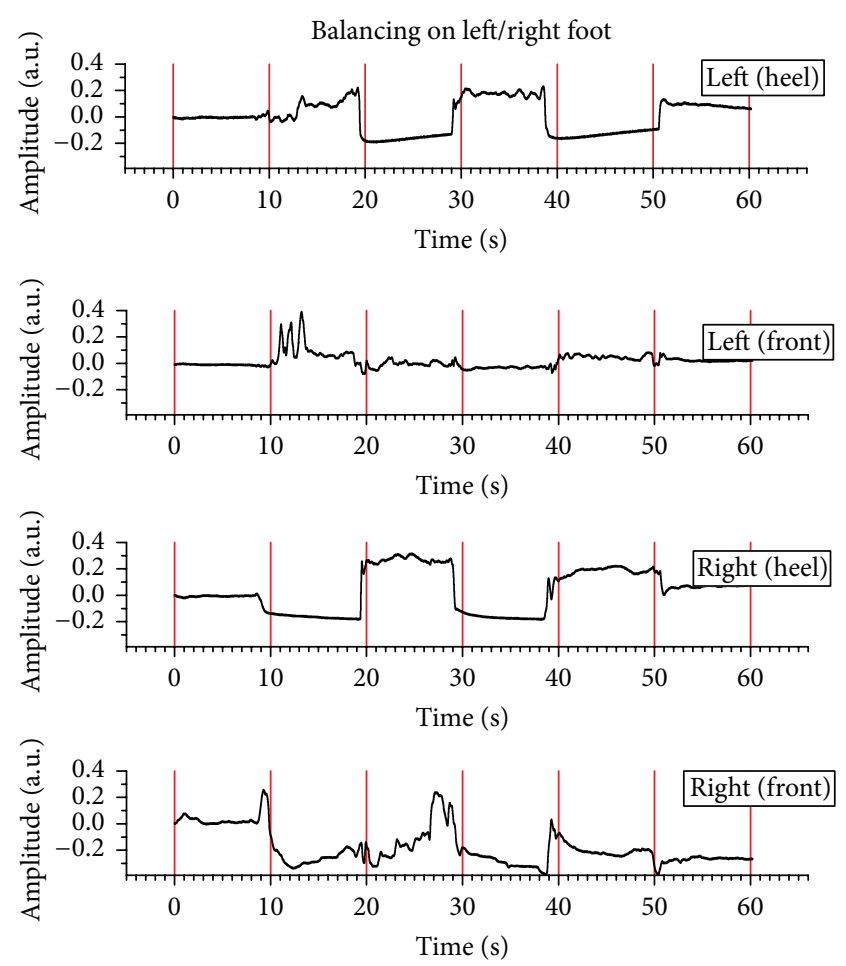

FiguRE 5: Standing pattern as a function of time for the 4 sensors.

amount of subjects in order to compare different heel patterns and understand if the differences between left and right come from the setup or from the normal gait of the subject.

But it is necessary to highlight that the second subject with known balancing problems was tested. Graphical results are found in Figures 10 and 11. By comparing both balancing setups (front/back and left/right) it can be seen that, even with different normalization or time values, MEMS sensors sense the change of pattern with high sensitivity. The gait pattern of this subject could give very interesting information about how MEMS can distinguish between healthy and diseased patients. Thus, our experimental results for standing, jumping, gait, and balancing patterns show that MEMS sensors with the adequate characteristics are a promising technique to measure foot plantar pressure and analyse the different pressure continuously over time in different subjects.

\section{Discussion}

This study was carried out to analyse the technical parameters of MEMS sensors and to determine whether these sensors were suitable for the study of foot plantar pressure.

The results show that voltage differences in all presented setups are in agreement with our expectations. Lifting a leg causes the MEMS sensor to present a smaller voltage reading than when the foot hits the ground, and the same happens during the two balancing trials (front/back and left/right). Voltage differences also increase when weight is added or during jumping. By recording different movement patterns, it is clearly possible to understand what movement 

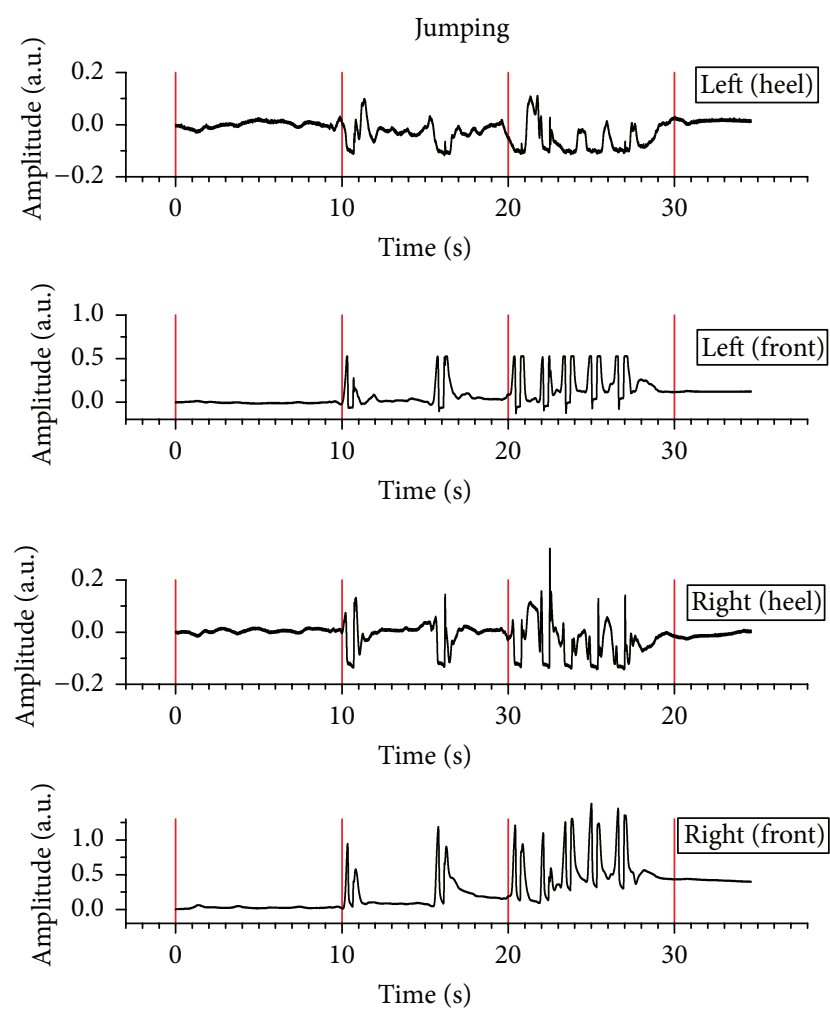

FIGURE 6: Jumping pattern as a function of time for the 4 sensors.

the subject is performing. It can be seen that balancing has a certain periodicity to it, with softer left/right movements than front/back movements. This can be related to the ease of the action.

The results should be compared to those presented in previous literature to determine if the measured pressure is within the normal range for foot plantar pressure. However, in this analysis, the initial voltage-pressure calibration was not performed, so the results only appear as a voltage difference and not as a pressure value. For future tests, this initial calibration step should not be avoided, as it opens the door to comparisons and to the acceptance of the sensors as suitable. The most significant tests in this study were the balancing tests. Balance is a generic term describing the dynamics of body posture to prevent falling [22]. Balance in humans is controlled by the vestibular system and is directly related to many disorders that can hamper daily-life activities due to brain, ear, or white matter issues [23-25]. As balance is a very common complaint (for the elderly in particular), many researchers have focused on improving it using different treatments. At this moment, many clinicians use in-sole measurements similar to the ones used in this study to analyse and improve balance and even to determine a personalised treatment for each patient. Studies have revealed that soles are very useful for this purpose [26]. The results according to the two balancing setups presented here show that MEMS sensors have the capability to sense balance with high accuracy. Both the pattern and voltage values correspond to a swinging movement from side to side or

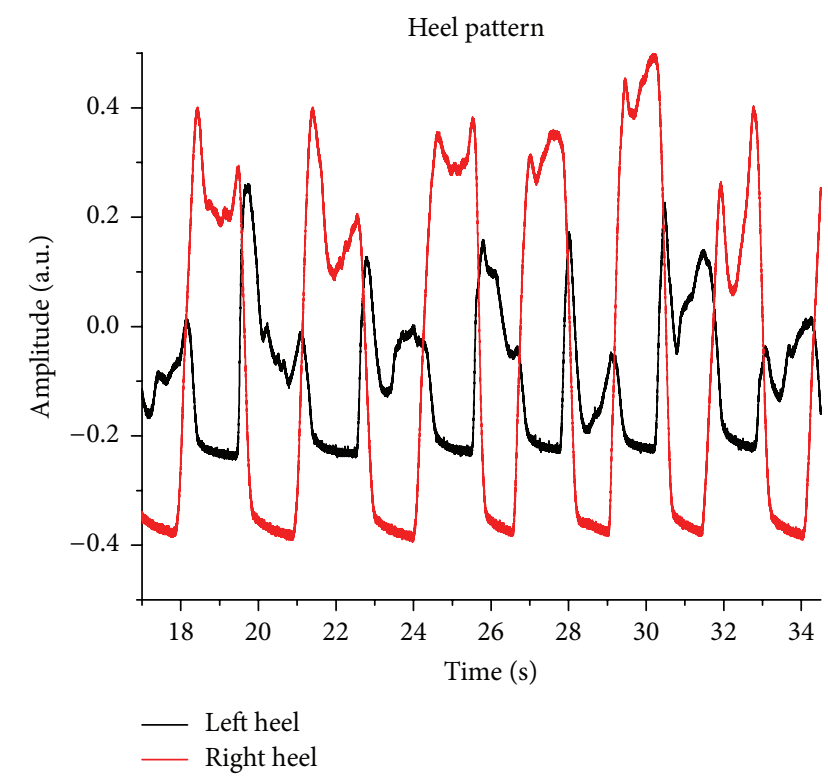

FIGURE 7: Voltage values obtained during gait analysis for sensors 1 and 3, following the heel pattern of gait. Both measurements are performed by a MPX2202A sensor, with $200 \mathrm{kPa}$ range.

front to back. These results could be further analysed in pressure units after calibration. These tests open a very interesting research field, involving the use of thin MEMS sensors embedded in an insole in a clinical environment to measure with high accuracy, repeatability, and reliability the pressure (and consequently balance) in different areas of feet to improve diagnosis and treatment.

However, although the results seem promising, the methods used in this experiment could be improved. According to literature $[27,28]$ heel pressure is normally higher than front pressure while walking, and this difference is more important while standing. This should be taken into account. Moreover, it seemed that the setup saturated in the jumping tests. As said, ranges close to $1900 \mathrm{kPa}$ should be used to measure foot plantar pressure [21]. As seen in Table 1, the tested MEMS sensors have a limitation which is directly related to foot plantar pressure; thickness is higher than other sensors. Tested sensors are $5 \mathrm{~mm}$ thick while others are only $0.15 \mathrm{~mm}$. Nevertheless, it can be said that MEMS sensors seem to be highly useful for the study of foot plantar pressure. Nowadays, MEMS pressure sensors are commercially available but their potential for foot plantar pressure studies has not been fully exploited. The commercialization process may be rapidly enhanced and expanded by overcoming these limits, for example, by developing a flexible capsule packaging system [17].

\section{Conclusion}

MEMS sensor technology possesses characteristics such as high linearity and pressure range and negligible hysteresis that makes it highly suitable for foot plantar pressure measurements. Furthermore, experiments presented in this 

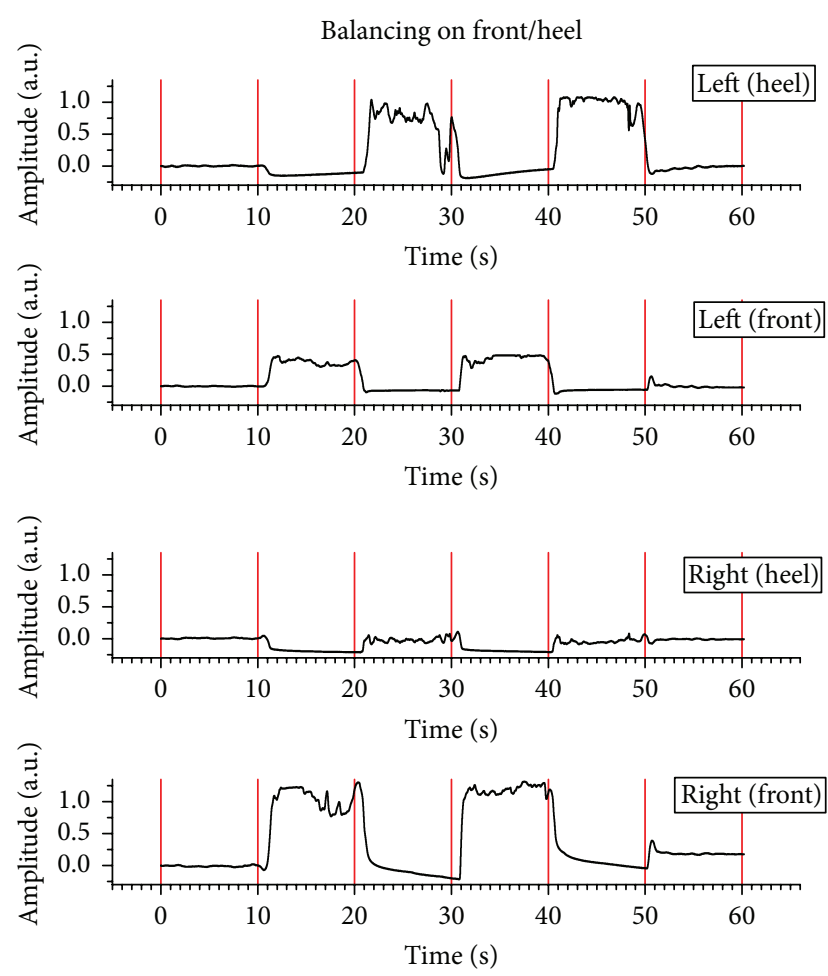

FIGURE 8: Balancing pattern from the front to the heel as a function of time for the 4 sensors.
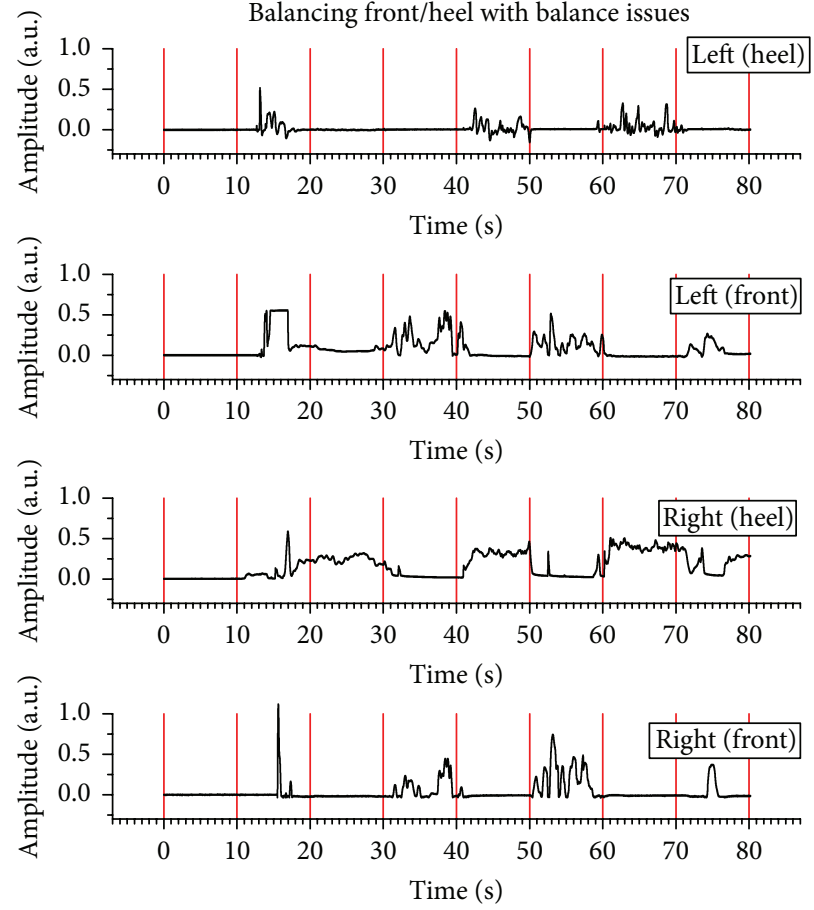

FIGURE 10: Balancing pattern from the front to the heel as a function of time for the 4 sensors with a subject suffering from balance disorders.
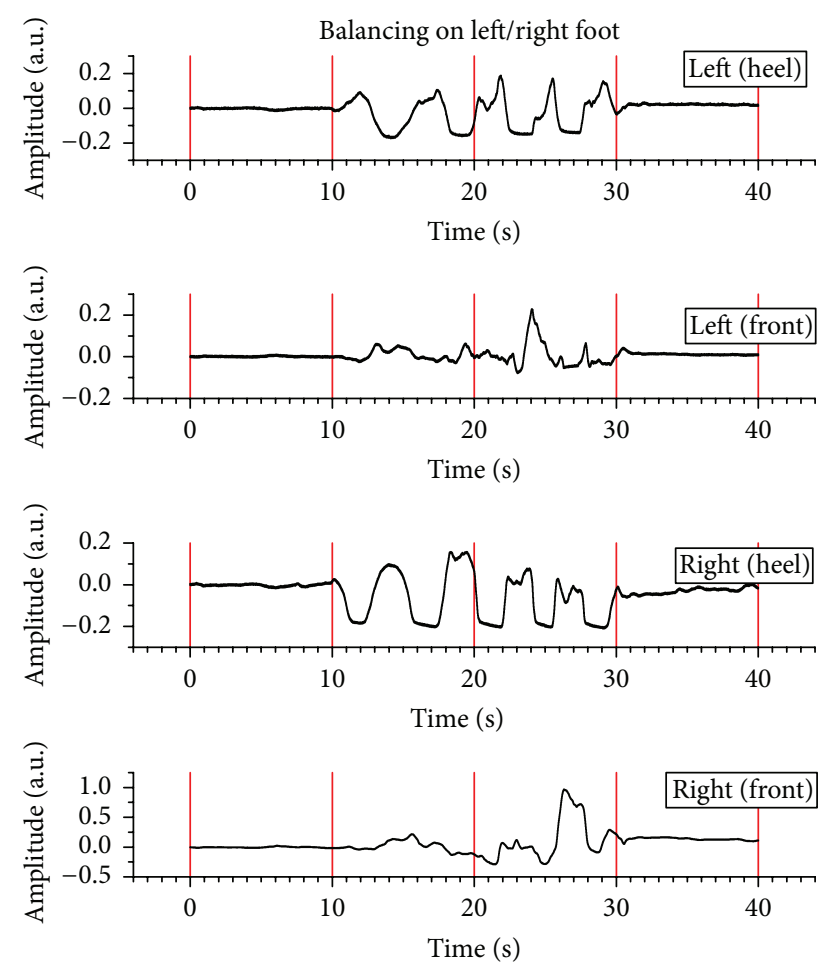

FIGURE 9: Balancing pattern from the left to the right as a function of time for the 4 sensors.
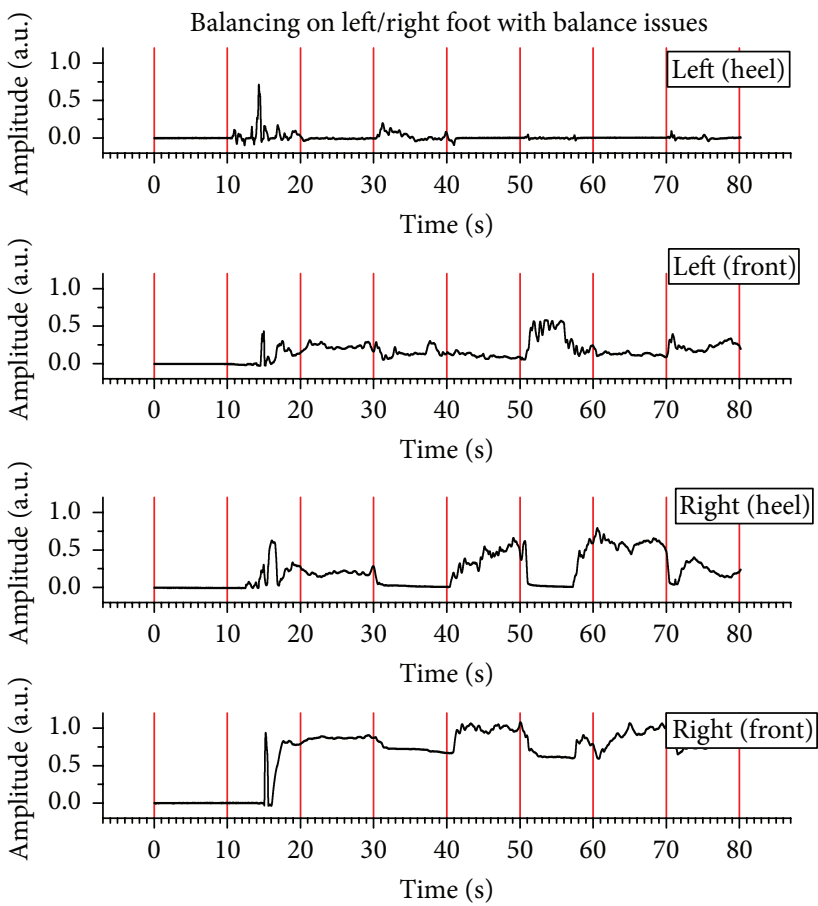

FIGURE 11: Balancing pattern from the left to the right as a function of time for the 4 sensors with a subject suffering from balance disorders. 
paper demonstrate the applicability of MEMS sensors to body balance measurements, based on their ability to measure pressure continuously. At the moment of writing, the utilization of MEMS technology in biomechanical applications of this type is relatively new and should be further studied.

\section{Conflict of Interests}

The authors declare that there is no conflict of interests regarding the publication of this paper.

\section{References}

[1] J. R. Mackey and B. L. Davis, "Simultaneous shear and pressure sensor array for assessing pressure and shear at foot/ground interface," Journal of Biomechanics, vol. 39, no. 15, pp. 2893-2897, 2006.

[2] P. R. Cavanagh, F. G. Hewitt Jr., and J. E. Perry, "In-shoe plantar pressure measurement: a review," The Foot, vol. 2, no. 4, pp. 185194, 1992.

[3] M. N. Orlin and T. G. McPoil, "Plantar pressure assessment," Physical Therapy, vol. 80, no. 4, pp. 399-409, 2000.

[4] Y. Wahab, Design and implementation of MEMS biomechanical sensors for real-life measurements of gait parameters [Ph.D. thesis], Victoria University, Melbourne, Australia, 2009.

[5] Vectron, "MEMS clock oscillators," October 2015, http://www .vectron.com/products/mems/mems_index.htm.

[6] "MEMSnet: a MEMS Clearinghouse and information portal for the MEMS and Nanotechnology community," October 2015, https://www.memsnet.org/mems/applications.html.

[7] SolidState Technology, "MEMS devices for biomedical applications," 2015, http://electroiq.com/blog/2013/10/mems-devicesfor-biomedical-applications/.

[8] Segway Inc.s Human Transporter (HT) models, 2015, https:// www.msu.edu/ luckie/segway/iBOT/iBOT.html.

[9] Tekscan, October 2015, http://www.tekscan.com/medical/ system-fscanl.html.

[10] Y. Wahab and N. A. Bakar, MEMS Biomedical Sensor for Gait Analysis, INTECH Open Access Publisher, 2011.

[11] E. Gassmann and A. Gries, "Handbook Electronic Pressure Measurement," Basics, Applications 11 and Instrument Selection, WIKA, 2010.

[12] A. H. Abdul Razak, A. Zayegh, R. K. Begg, and Y. Wahab, "Foot plantar pressure measurement system: a review," Sensors, vol. 12, no. 7, pp. 9884-9912, 2012.

[13] MPX2202 data sheet, 2012, http://cache.freescale.com/files/ sensors/doc/data_sheet/MPX2202.pdf.

[14] MPX5999D data sheet, 2015, http://cache.freescale.com/files/ sensors/doc/data_sheet/MPX5999D.pdf?pspll=1.

[15] A. A. Kalamdani, Development and characterization of a highspatial-temporal-resolution foot-sole-pressure measurement system [Ph.D. thesis], Carnegie Mellon University, Pittsburgh, Pa, USA, 2006.

[16] A. Berns, U. Buder, E. Obermeier, A. Wolter, and A. Leder, "AeroMEMS sensor array for high-resolution wall pressure measurements," Sensors and Actuators A: Physical, vol. 132, no. 1, pp. 104-111, 2006.

[17] N. K. Lee, R. S. Goonetilleke, Y. S. Cheung, and G. M. So, "A flexible encapsulated MEMS pressure sensor system for biomechanical applications," Microsystem Technologies, vol. 7, no. 2, pp. 55-62, 2001.

[18] Voler Systems, "How to avoid big errors using accelerometers," 2011, http://www.volersystems.com/news/newsletters/30v2011/125-how-to-avoid-big-errors-using-accelerometers.

[19] C. Payton and R. Bartlett, Eds., Biomechanical Evaluation of Movement in Sport and Exercise: The British Association of Sport and Exercise Sciences Guide, Routledge, 2007.

[20] H. Hsiao, J. Guan, and M. Weatherly, "Accuracy and precision of two in-shoe pressure measurement systems," Ergonomics, vol. 45, no. 8, pp. 537-555, 2002.

[21] G. M. Caputo, P. R. Cavanagh, J. S. Ulbrecht, G. W. Gibbons, and A. W. Karchmer, "Assessment and management of foot disease in patients with diabetes," The New England Journal of Medicine, vol. 331, no. 13, pp. 854-860, 1994.

[22] D. A. Winter, "Human balance and posture control during standing and walking," Gait \& Posture, vol. 3, no. 4, pp. 193-214, 1995.

[23] D. L. Sturnieks, R. St George, and S. R. Lord, "Balance disorders in the elderly," Clinical Neurophysiology, vol. 38 , no. 6 , pp. 467478, 2008.

[24] F. B. Horak, S. M. Henry, and A. Shumway-Cook, "Postural perturbations: new insights for treatment of balance disorders," Physical Therapy, vol. 77, no. 5, pp. 517-533, 1997.

[25] H. Baezner, C. Blahak, A. Poggesi et al., "Association of gait and balance disorders with age-related white matter changes. The LADIS study," Neurology, vol. 70, no. 12, pp. 935-942, 2008.

[26] D. M. Corbin, J. M. Hart, P. O. McKeon, C. D. Ingersoll, and J. Hertel, "The effect of textured insoles on postural control in double and single limb stance," Journal of Sport Rehabilitation, vol. 16, no. 4, pp. 363-372, 2007.

[27] T. A. Bacarin, I. C. N. Sacco, and E. M. Hennig, "Plantar pressure distribution patterns during gait in diabetic neuropathy patients with a history of foot ulcers," Clinics, vol. 64, no. 2, pp. 113-120, 2009.

[28] S. L. Goffar, R. J. Reber, B. C. Christiansen et al., "Changes in dynamic plantar pressure during loaded gait," Physical Therapy, vol. 93, no. 9, pp. 1175-1184, 2013. 


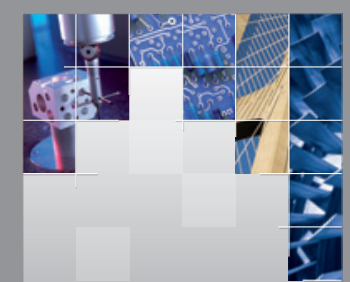

\section{Enfincering}
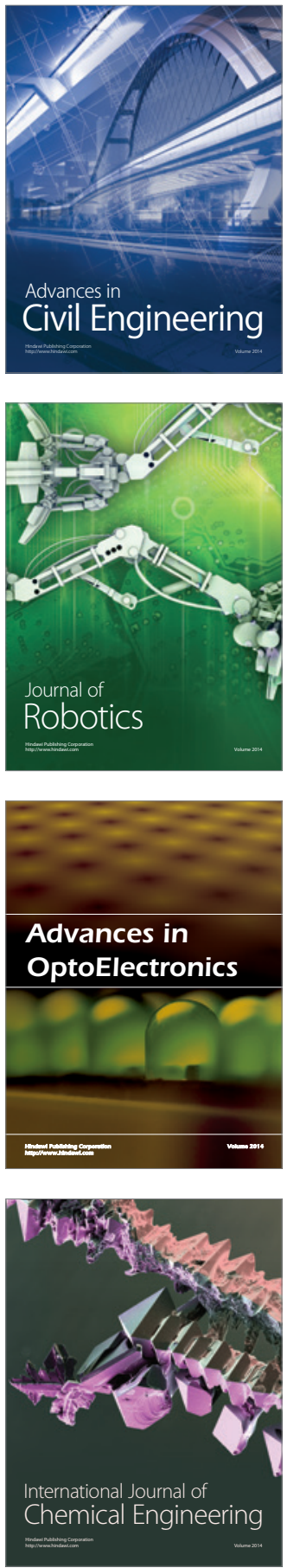

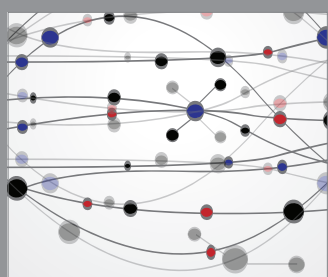

The Scientific World Journal

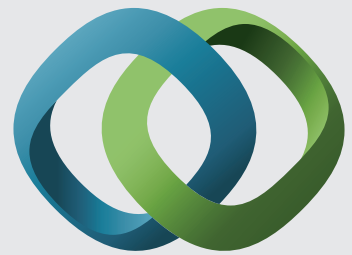

\section{Hindawi}

Submit your manuscripts at

http://www.hindawi.com
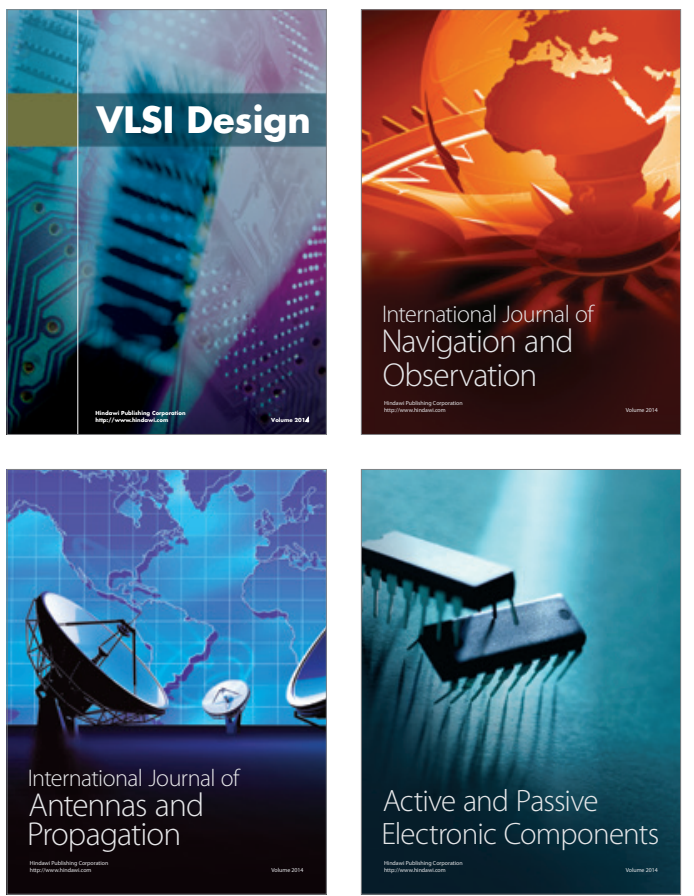
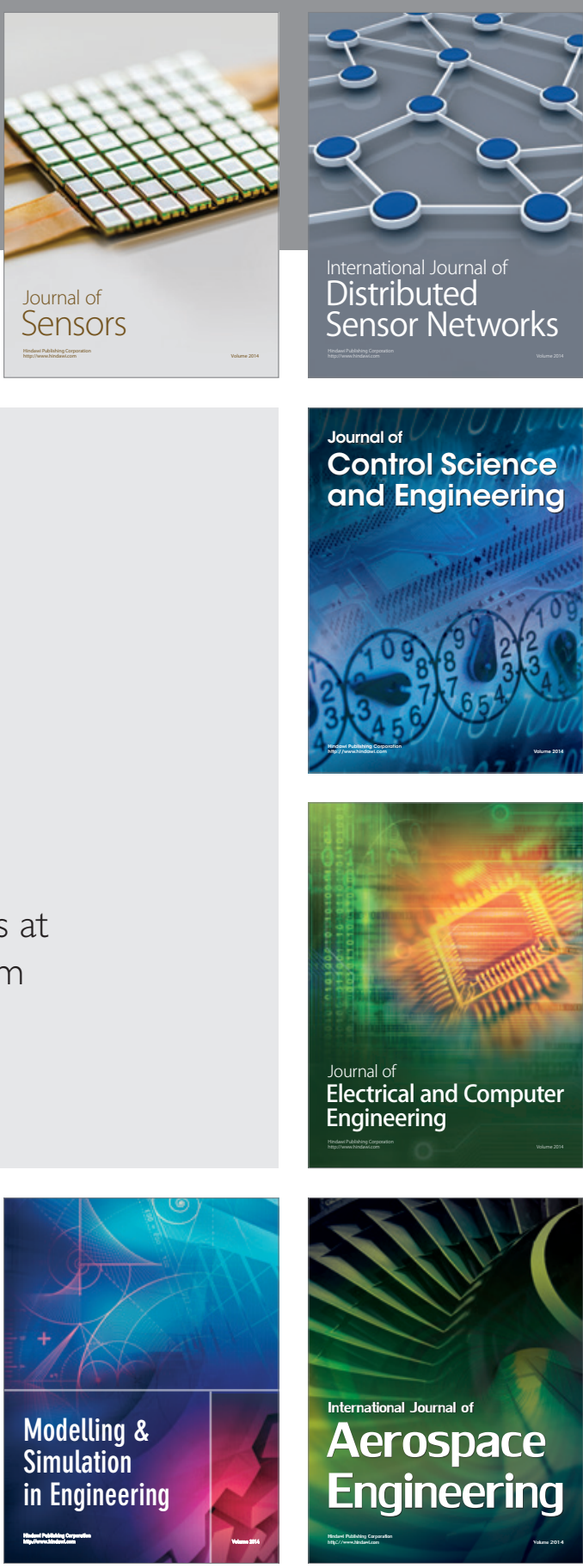

International Journal of

Distributed

Sensor Networks

Journal of

Control Science

and Engineering
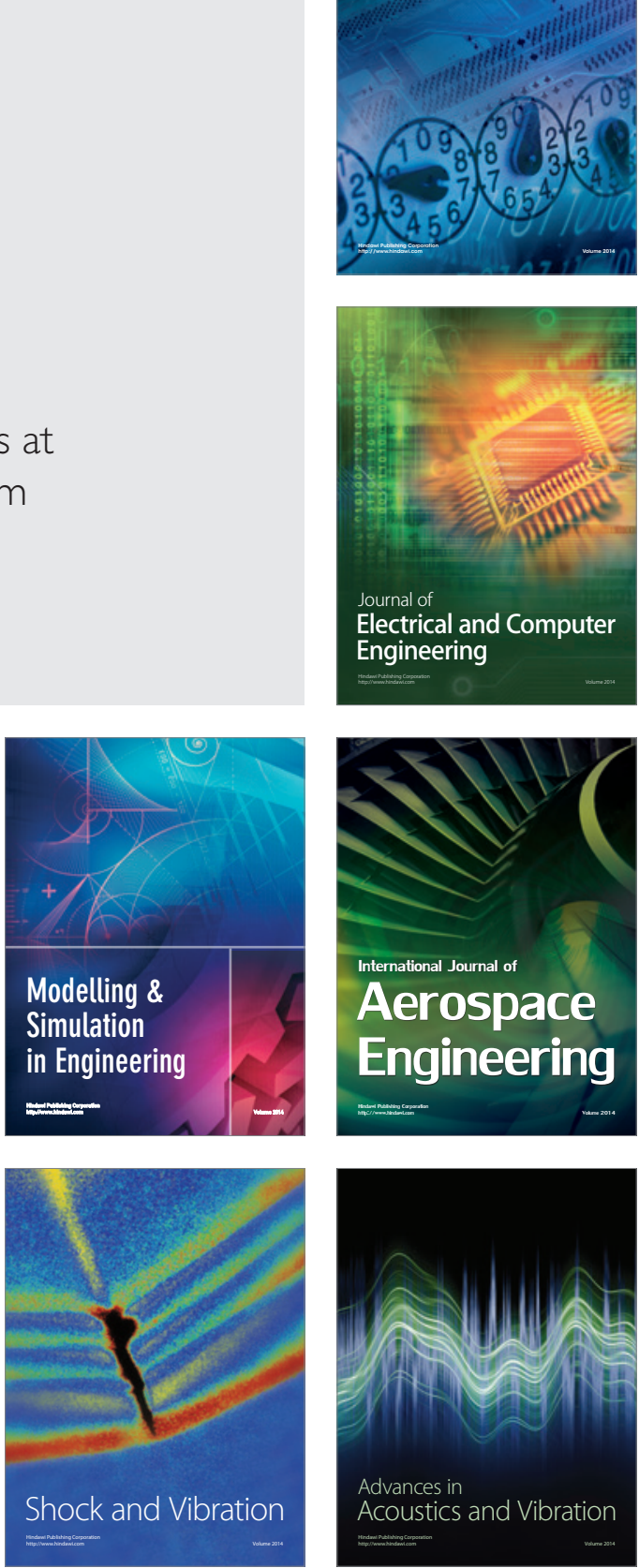